\title{
Gestão do Conhecimento e Geração de Benefícios Intermediários em Programas Públicos: 0 Caso do Programa Mãe Curitibana
}

\author{
Knowledge Management and Generation of Intermediary Benefits in Public \\ Programs: The case of Curitiban Mother Program
}

\author{
Márcia Helena Vieira Carvilhe ${ }^{1}$ \\ Heitor José Pereira ${ }^{2}$ \\ Heitor Takashi Kato ${ }^{3}$
}

\section{Resumo}

Este artigo tem por objetivo apresentar, de maneira sucinta, resultados de estudo de caso sobre contribuições dos processos de Gestão do Conhecimento (GC) para a geração de benefícios intermediários no âmbito do Programa Mãe Curitibana, na Secretaria Municipal de Saúde de Curitiba (SMS). Para a realização da pesquisa optou-se pela metodologia qualitativa e descritiva. A pesquisa de campo foi realizada no período de outubro de 2003 a junho de 2004 . Resultados da pesquisa possibilitam constatar uma grande quantidade de atividades não formalizadas de GC desenvolvidas desde a fase de formulação do programa, as quais vêm contribuindo, significativamente, para geração de benefícios no funcionamento do programa, na prestação dos serviços ao público alvo, bem como nas reações externas ao programa. Por outro lado, informações relativas ao modo e à freqüência com que os processos de GC investigados vêm sendo realizados remetem a diversas possibilidades de aperfeiçoamento, com vistas a contribuir de maneira mais efetiva para a geração de benefícios no âmbito do Programa Mãe Curitibana.

Palavras-chave: Gestão do Conhecimento, Benefícios da Gestão do Conhecimento, Programas Públicos

\begin{abstract}
This article presents, briefly, the results of a case study about contributions of the Knowledge Management (KM) processes to the generation of intermediary benefits in the scope of the Curitiban Mother Program of the Municipal Health Department of Curitiba. For the research performance, a qualitative and descriptive methodology was used. The field research was performed in the timeframe between October, 2003 and June, 2004. The research results evidence a great number of KM non-formalized activities developed since the program formulation stage, which have been significantly contributing to the benefit production along the program performance, as well as service rendering to the target public and external reactions to the program. On the other hand, information regarding the manner and frequency the investigated KM processes have been performing lead to various improvement possibilities, aiming at a more effective contribution to the benefit production in the scope of the Curitiban Mother Program.
\end{abstract}

Keywords: Knowledge Management, Knowledge Management Benefits, Public Programs.

\footnotetext{
${ }^{1}$ Mestre em Administração Estratégica pela PUCPR. Gerente de Informações no Depto de Planejamento da Secretaria Municipal de Educação de Curitiba. Endereço: Avenida João Gualberto, 623 - $6^{\circ}$ andar - Torre A - Alto da Glória - Curitiba - PR - Brasil - - CEP: 80.030.000. E-Mail : arciacarvilhe@sme.curitiba.pr.gov.br

${ }^{2}$ Doutor em Administração de Empresas pela EAESP/FGV. Professor da FGV Management . Endereço: Rua dos Acauãs, 92 - Residencial Andorinhas - Alphaville Graciosa - Pinhais - PR - Brasil - CEP: 83327-156 .E-Mail : heitorrh@nutecnet.com.br

${ }^{3}$ Doutor em Administração de Empresas pela EAESP/FGV. Professor Adjunto do PPAD/CCSA da PUCPR. Endereço: Rua Imaculada Conceição, 1155 - Prado Velho - Curitiba - PR - Brasil - CEP: 80215-901. E-Mail: heitor.kato@pucpr.br
}

Artigo recebido em janeiro de 2006 e aceito para publicação em dezembro de 2006 


\section{Introdução}

O conhecimento vem sendo apontado como um recurso vital às organizações, pela possibilidade de contribuir para a obtenção de vantagens competitivas sustentáveis, para a agregação de valor aos produtos, ou para a melhoria da qualidade na prestação de serviços, impondo às organizações a necessidade de administrá-lo de maneira competente. Com isto, o tema da Gestão do Conhecimento (GC) vem despertando grande interesse no meio acadêmico, consolidando uma bagagem teórica significativa, bem como respaldando diversas experiências de implantação de projetos de Gestão do Conhecimento em organizações das esferas pública e privada.

Especificamente no âmbito da saúde pública, algumas iniciativas estruturadas vêm sendo implementadas em torno do tema Gestão do Conhecimento (BATISTA, 2005; BATISTA, 2004; BRASIL, 2004; CARVALHO, 2003; BRASIL, 2003). Entre outros tópicos, a questão dos benefícios decorrentes de atividades de Gestão do Conhecimento vem sendo alvo de estudos e discussões, com abordagens sob diferentes perspectivas (TERRA, 2001; TEIXEIRA FILHO, 2000; DAVENPORT E PRUSAK, 1998; STEWART, 1998; PELUFFO E CATALAN CONTRERAS, 2002), merecendo destaque as classificações de benefícios propostas por Wiig (1999, 2004) e Skyrme (2004).

Ao mesmo tempo, observa-se que, independentemente de um processo formalizado de Gestão do Conhecimento, ao longo das diferentes fases do ciclo de vida de programas e projetos públicos, são realizadas atividades relacionadas à informação e ao conhecimento que muito se assemelham às práticas descritas por autores que abordam a GC como um processo organizacional, o que denominamos práticas não formalizadas de Gestão do Conhecimento.

Tais iniciativas vêm reforçar o interesse em aprofundar conhecimentos acerca da aplicação da GC no âmbito de programas e projetos públicos, a exemplo do Mãe Curitibana, voltado à saúde materno-infantil, desenvolvido pela Secretaria Municipal de Saúde (SMS) de Curitiba, desde março de 1999 - quando foi lançado oficialmente. A investigação busca focar, sobretudo, benefícios que podem advir dessas práticas, sejam elas formalizadas ou não.

Dentro desse contexto, este trabalho teve como objetivo geral verificar se os processos não formalizados de Gestão do Conhecimento, praticados nas diferentes fases do ciclo de vida do Programa Mãe Curitibana na Secretaria Municipal de Saúde de Curitiba, no período de 1998 a 2004, vêm contribuindo para a geração de benefícios intermediários no âmbito deste programa.

\section{Revisão de Literatura}

A seguir, são abordados tópicos considerados fundamentais para respaldar a pesquisa: Fases do Ciclo de Vida de Programas/Projetos; Gestão do Conhecimento; e Benefícios da Gestão do Conhecimento.

\section{Fases do Ciclo de Vida de Programas/Projetos}

Desde o início dos anos 90, o gerenciamento do ciclo de vida de projetos vem se destacando como um dos modelos utilizados para explicar o que é a gerência de projetos. De acordo com esse modelo, os projetos são desenvolvidos dentro de um intervalo de tempo conhecido como ciclo de vida, dentro do qual eles são projetados para serem concebidos e finalizados (DINSMORE, 1999).

A literatura sobre ciclo de vida de projetos apresenta-se bastante diversificada no que diz respeito às fases que o compõem, sendo algumas definições mais aplicadas a programas desenvolvidos em empresas privadas; e outras, a programas públicos (DINSMORE, 1999; VALERIANO, 1998; VERZUH, 2000; CEPAL/ILPES, 2003). Merece nosso destaque a definição da CEPAL/ILPES (2003) destinada, especificamente, a projetos sociais, aproximando-se mais da realidade da organização pesquisada. 
Os projetos sociais são definidos como a unidade mínima de aplicação de recursos para o alcance de um ou mais objetivos específicos, os quais possuem um público-alvo definido, localização espacial determinada, e tempo de início e fim previstos. Já os programas podem ser definidos como conjuntos de projetos que perseguem os mesmos objetivos. Dessa maneira, os programas podem ser analisados por meio dos projetos que os integram (CEPAL, 1998).

Para efeitos desta pesquisa, os termos "programa" e "projeto" serão utilizados como sinônimos, visto que o programa em estudo reúne as características de projetos explicitadas acima, além de não possuir um conjunto de projetos a ele vinculados, o que seria típico de um programa.

Para a CEPAL/ILPES (2003), o ciclo de vida dos projetos compreende o processo de transformação de uma idéia para resolver um problema até o início do funcionamento ou implantação da solução para tal problema, distinguindo-se três fases sucessivas: pré-investimento, investimento e operação.

Ainda que diferentes autores definam o ciclo de vida dos projetos de maneira distinta, tais definições contemplam pelo menos três fases, denominadas neste artigo de: formulação, estruturação e operação. A fase de formulação, denominada por alguns autores fase conceitual, de definição ou de pré-investimento, envolve atividades relacionadas à concepção, definição e avaliação de viabilidade da idéia que se pretende pôr em prática. A fase de estruturação, denominada fase de planejamento, investimento ou implementação, abrange atividades relacionadas ao desenho e execução de obras físicas, e programação detalhada das atividades prévias ao início do funcionamento do programa. Por fim, a fase de operação, também chamada fase de implantação, é o momento em que se inicia o funcionamento do projeto ou programa, com a oferta do produto ou serviço, gerando-se os benefícios previstos nas fases anteriores (DINSMORE, 1999; VALERIANO, 1998; VERZUH, 2000; CEPAL/ILPES, 2003).

\section{Gestão do Conhecimento}

Entre as diversas abordagens voltadas à implantação de projetos de Gestão do Conhecimento nas organizações, merece destaque a abordagem de alguns autores que apresentam um detalhamento referente aos subprocessos que compõem o processo de Gestão do Conhecimento, aqui denominados genericamente de processos (STOLLENWERK, 2002; PROBST; RAUB; ROMHARDT, 2002; DAVENPORT; PRUSAK, 1998a, 1998b; PELUFFO A. e CATALAN CONTRERAS, 2002).

Stollenwerk (2002) propõe um Modelo Genérico de Gestão do Conhecimento que contempla sete processos: identificação; captura; seleção e validação; organização e armazenagem; compartilhamento; aplicação e criação. Este modelo conta, ainda, com quatro fatores facilitadores: liderança; cultura organizacional; mediação e recompensa; e tecnologia da informação e comunicação, os quais não serão examinados neste estudo.

Utilizando como referência o Modelo Genérico de Gestão do Conhecimento exposto acima, são apresentados, a seguir, os principais conceitos relativos aos processos de GC abordados por Stollenwerk (2002), considerados processos básicos de GC a serem investigados na pesquisa, acrescentando-se, ainda, a eles, conceitos comuns abordados por Probst, Raub e Romhardt (2002), Davenport e Prusak (1998a, 1998b), Peluffo A. e Catalan Contreras (2002).

- Identificação: tem, como ponto de partida, as estratégias organizacionais, a partir das quais se identificam as competências críticas e as áreas de conhecimento que as sustentam. Abrange, ainda, a identificação das lacunas entre as competências existentes e as necessárias, e das fontes de conhecimento internas e externas, assim como a programação de soluções para o desenvolvimento e/ou manutenção destas competências;

- captura (ou aquisição): abrange uma diversidade de atividades voltadas ao desenvolvimento e/ou reciclagem das competências necessárias, mediante aquisição de conhecimentos, habilidades e experiências junto às fontes internas e externas identificadas anteriormente. Este processo, assim como o de criação do conhecimento, possibilita agregar conhecimento novo na organização; 
- seleção e validação: está fortemente associado ao processo anterior de captura. Visa a filtrar o conhecimento, avaliar sua qualidade e sintetizá-lo para fins de aplicação futura. Nem todo o conhecimento gerado, recuperado ou desenvolvido deve ser armazenado na organização;

- organização e armazenagem (ou sistematização): compreende práticas voltadas a codificar, formalizar, reter ou dar permanência aos conhecimentos que são críticos para a organização, de maneira a disponibilizá-los aos interessados. Embora se ressalte o papel das tecnologias da informação e da comunicação, este processo abrange tanto a sistematização de conhecimentos em material impresso, quanto em meio eletrônico;

- compartilhamento: engloba desde o acesso e distribuição de informações e conhecimentos por meio da utilização de recursos de tecnologia da informação e da comunicação até o compartilhamento de conhecimentos, habilidades e experiências mediante contato face a face. Tem, como foco primordial, a ampla difusão do conhecimento dentro da organização, por meio do compartilhamento de conhecimentos explícitos e tácitos disponíveis;

- aplicação (ou uso): trata da utilização do conhecimento, destacando que o objetivo integral da Gestão do Conhecimento é assegurar que o conhecimento presente em uma organização seja aplicado produtivamente em seu benefício. Infelizmente, a identificação e a distribuição bem-sucedidas de conhecimento não garantem que ele será utilizado nas atividades diárias da organização;

- criação (ou produção): tem como foco a agregação de conhecimentos novos na organização. Abrange todos os esforços direcionados à criação, à produção ou ao desenvolvimento de novas idéias, capacidades, produtos e serviços no interior da organização. Baseia-se, para tanto, em atividades que favoreçam a criatividade e a inovação (STOLLENWERK, 2002; PROBST; RAUB; ROMHARDT, 2002; DAVENPORT; PRUSAK, 1998a, 1998b; PELUFFO A. e CATALAN CONTRERAS, 2002).

\section{Benefícios da Gestão do Conhecimento}

A literatura sobre Gestão do Conhecimento apresenta uma grande diversidade de conceitos e de enfoques. Por outro lado, observa-se que, de modo geral, diferentes autores relacionam iniciativas de Gestão do Conhecimento à agregação de valor aos bens e/ou serviços produzidos pelas organizações (TERRA, 2001; TEIXEIRA FILHO, 2000; DAVENPORT E PRUSAK, 1998; STEWART, 1998; WIIG, 1999, 2000; SKYRME, 2004); PELUFFO E CATALAN CONTRERAS, 2002).

Nessa linha, a geração de benefícios por meio de iniciativas de Gestão do Conhecimento vem sendo abordada sob diferentes perspectivas, que enfatizam desde benefícios que repercutem no interior da organização, até aqueles que impactam o mercado ou a sociedade.

Segundo Wiig (1999), para facilitar a identificação dos fatores que podem resultar em custos e benefícios desejáveis, de atividades de Gestão do Conhecimento nas organizações, tem sido útil uma representação gráfica de cadeias de efeito causal, que vão da atividade inicial aos benefícios finais. Estes benefícios são demonstrados como uma cadeia de eventos lineares que se iniciam com a decisão gerencial de desenvolver e instalar uma atividade de Gestão do Conhecimento, desdobrando-se em efeitos e benefícios diretos, intermediários e finais (WIIG, 2004), conforme representado na Figura 1: 


\section{Figura 1 - Cadeia de benefícios/efeitos de atividades de gestão do conhecimento}

\begin{tabular}{|c|c|c|c|c|c|}
\hline $\begin{array}{l}\text { ATIVIDADES DE } \\
\text { GESTÃO DO } \\
\text { CONHECIMENTO }\end{array}$ & $\begin{array}{l}\text { BENEFÍCIOS } \\
\text { DIRETOS: } \\
\text { Efeitos imediatos } \\
\text { das atividades de } \\
\text { GC na organização }\end{array}$ & $\sqrt{1}$ & \begin{tabular}{|l|} 
BENEFÍCIOS \\
INTERMEDIÁRIOS \\
Efeitos e Benefícios internos \\
(Foco na operação) \\
Benefícios no Atendimento (Foco \\
nos Produtos e Serviços) \\
Reações e Benefícios Externos \\
(Foco no Mercado e no \\
Consumidor)
\end{tabular} & 4 & $\begin{array}{l}\text { BENEFÍCIOS } \\
\text { FINAIS: } \\
\text { Efeitos } \\
\text { relacionados às } \\
\text { metas estratégicas } \\
\text { da organização }\end{array}$ \\
\hline
\end{tabular}

FONTE: adaptado de Wiig $(1999,2004)$.

Os benefícios diretos da Gestão do Conhecimento abrangem os efeitos mais imediatos das atividades de GC na organização, tais como facilidade de acesso aos conhecimentos, ou a ampliação do compartilhamento. Os efeitos intermediários englobam os relativos às atividades de GC nos processos de trabalho (foco nas operações), nos produtos e serviços (foco nos produtos e serviços), bem como no ambiente externo à organização (foco no mercado e no consumidor). Já os benefícios finais incluem efeitos relacionados às metas estratégicas da organização, tais como lucratividade, imagem de mercado, entre outros (WIIG, 2004). Dentro da mesma lógica de pensamento, Skyrme (2004) classifica os benefícios da GC em três classes: do conhecimento, intermediários e organizacionais.

No tocante à busca de um serviço público mais competente e efetivo, Wiig (2000) enfatiza a importância significativa da administração do conhecimento na obtenção de melhores serviços públicos. $\mathrm{O}$ autor cita alguns exemplos de efeitos intermediários e finais que podem ser obtidos com a implantação de atividades de GC: melhores produtos e serviços, maior efetividade interna, custos mais baixos, melhores relações com os funcionários, aumento de valor para os clientes, aumento de valor para os stakeholders, maior alcance dos objetivos e aumento da viabilidade do empreendimento. Para se conseguir atingir estes objetivos, enfatiza a necessidade da identificação prévia das atividades a serem implantadas e da previsão dos benefícios resultantes.

A cadeia de efeitos ou benefícios de atividades de Gestão do Conhecimento proposta por Wiig (1999; 2004), bem como as classes de benefícios apontadas por Skyrme (2004), fornecem, assim, um embasamento para as possíveis investigações acerca dos impactos gerados por atividades relacionadas à GC, a exemplo do balanced scorecard, utilizado como modelo para mensuração dos impactos da GC em um estudo de caso realizado na UK's Financial Services Authority (ROS, 2003). Sob esta ótica, a classificação de benefícios da GC apresentase como uma possibilidade à identificação das contribuições dos processos de GC no âmbito de organizações públicas ou privadas.

Com base nos conceitos abordados na revisão de literatura, elaborou-se o modelo conceitual que embasou a pesquisa de campo, representado na Figura 2. 
Figura 2 - Modelo conceitual da pesquisa de campo

FASES DO CICLO DE VIDA DE PROGRAMAS

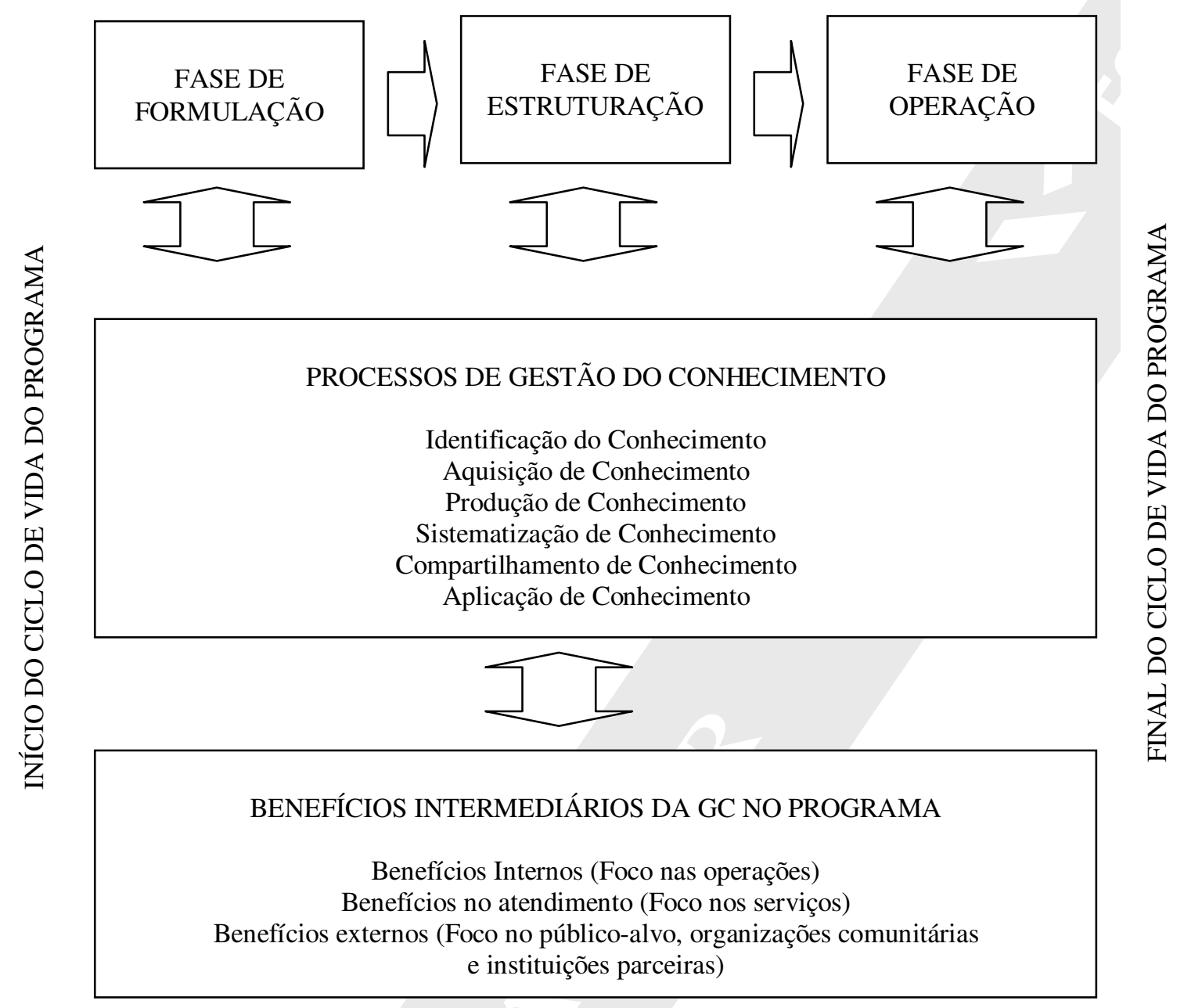

\section{Metodologia}

Adotou-se, como estratégia, para efetuar esta pesquisa, a realização de estudo de caso, que, para Yin (2001, p. 32), "é um estudo empírico que investiga um fenômeno atual dentro do seu contexto de realidade, quando as fronteiras entre o fenômeno e o contexto não são claramente definidas e no qual são utilizadas várias fontes de evidência"; e que, para Vergara (2000), está circunscrito a uma ou poucas unidades, entendidas essas como uma pessoa, uma empresa, um órgão público, uma comunidade ou mesmo um país, e tem caráter de profundidade e detalhamento.

O universo da pesquisa está circunscrito à equipe de profissionais que atuam no programa Mãe Curitibana, na Secretaria Municipal de Saúde de Curitiba, na coordenação do programa, nos níveis central e distrital (distritos sanitários); e nas Unidades de Saúde (US) do município de Curitiba, onde o programa é desenvolvido (94) no nível local.

A amostra caracteriza-se como não probabilística por julgamento, tendo sido selecionados, pelos pesquisadores, os participantes da população mais propensos a fornecer informações precisas (MALHOTRA, 2001). No âmbito da coordenação do programa foram selecionados para as entrevistas 6 (seis) do total de 11 (onze) profissionais que atuam na coordenação nos níveis central e distrital; e, no nível local, 32 (trinta e dois) 
profissionais que trabalham em 8 (oito) das 94 (noventa e quatro) Unidades de Saúde que desenvolvem o Programa Mãe Curitibana, sendo 1 (uma) Unidade de Saúde por Distrito Sanitário (DS), e 4 (quatro) profissionais por US; perfazendo um total de 38 (trinta e oito) profissionais entrevistados.

A amostra de profissionais dos níveis local e distrital foi definida em conjunto com a coordenação do Programa Mãe Curitibana, levando em conta os seguintes critérios: localização geográfica da Unidade de Saúde - sendo 1 (uma) por Distrito Sanitário-; Unidades de Saúde atuantes no programa desde o início de seu funcionamento; profissionais das respectivas US, com maior tempo de atuação no programa, sendo 1 auxiliar de enfermagem, 1 (um) enfermeiro, 1 (um) médico e 1 (uma) autoridade sanitária; e a disponibilidade dos profissionais em participar da entrevista.

A seleção da amostra de coordenadores também levou em conta o tempo de atuação no programa, bem como a disponibilidade de participar da entrevista, tendo sido escolhidos 2 (dois) profissionais atuantes na coordenação no nível central e 4 (quatro) coordenadores do nível distrital.

A coleta de dados baseou-se em diferentes fontes de evidência (YIN, 2001), tais como: a) documentação: publicações produzidas no âmbito do programa (protocolos, livros, revistas, boletins, jornais); relatórios de atividades, entre outros; b) registros em arquivos: informações sobre as Unidades de Saúde e profissionais da SMS; dados sobre treinamentos realizados no âmbito do programa (Centro de Estudos em Saúde), indicadores de resultados do programa (Centro de Epidemiologia), entre outros; c) entrevistas não estruturadas; d) entrevistas semi-estruturadas; e) observação direta: coleta informal de dados durante as visitas de campo para levantamento de dados secundários e primários.

A pesquisa de campo foi realizada em duas fases distintas. No período de outubro de 2003 a março de 2004, primeira fase da pesquisa, efetuou-se a coleta de dados secundários, por meio de documentação/registros; e de dados primários, por intermédio de entrevistas não estruturadas com profissionais que atuaram e/ou continuam atuando, direta ou indiretamente, na coordenação do programa, com vistas a levantar informações a respeito das fases do ciclo de vida do programa (formulação, estruturação e operação) e do modo como os processos de GC ocorreram ao longo destas fases.

Na segunda fase da pesquisa, que ocorreu no período de 30 de abril a 21 de maio de 2004, foram coletados dados primários por meio de entrevistas semi-estruturadas, gravadas, com profissionais das Unidades de Saúde, e da coordenação do programa, com o intuito de complementar informações levantadas na primeira fase, acerca dos processos de GC, bem como de coletar dados sobre possíveis contribuições destes processos para a geração de benefícios intermediários no Programa Mãe Curitibana.

O questionário era composto de 19 (dezenove) perguntas em Escala Likert, sendo 10 (dez) relacionadas aos processos de GC, e 9 (nove) referentes às possíveis contribuições destes processos para a geração de benefícios intermediários no âmbito do programa, com um campo para registro de comentários e impressões para cada uma das 19 questões. Tal questionário foi validado por meio de teste realizado em 3 (três) Unidades de Saúde (01 US por DS), num total de 15 (quinze) entrevistas.

Para cada uma das perguntas em Escala Likert, os entrevistados indicavam o grau de concordância ou discordância, conforme as variáveis e atitudes relacionadas ao objeto da pesquisa (SANTOS E BARROS, 2002). A partir do grau de concordância ou discordância obtido para cada uma das referidas perguntas, solicitaram-se, ainda, aos entrevistados, informações a respeito do modo e da freqüência com que vêm sendo realizadas; bem como suas impressões a respeito.

A coleta de dados primários e secundários explicitada acima foi precedida de solicitação formal à Secretaria Municipal de Saúde de Curitiba, mediante preenchimento de formulário específico, por meio do qual se obteve autorização para o início da pesquisa. Por solicitação da SMS, o projeto de pesquisa foi submetido ao parecer do Comitê de Ética em Pesquisa da Universidade, cumprindo o disposto na Resolução 196/96, do Conselho Nacional da Saúde, relativo à ética em pesquisas envolvendo seres humanos. 
Os dados secundários levantados foram analisados com base na técnica de análise documental, buscando-se descobrir elementos relevantes para a análise dos dados primários. Para facilitar a tabulação e favorecer a análise dos dados primários, utilizou-se o software SPHINX, que se constitui em um sistema para estudos qualitativos e quantitativos (FREITAS, 2002). Com base neste recurso, foram tabuladas as questões fechadas do formulário de entrevista, obtendo-se a distribuição percentual, a média e o desvio padrão, das respostas dos grupos entrevistados, bem como foram sistematizados os comentários dos entrevistados. A análise das informações coletadas por meio das entrevistas semi-estruturadas foi realizada com base na técnica de análise de conteúdo (BARDIN, 1977).

\section{Apresentação e Análise dos Resultados}

A apresentação e a análise dos resultados do estudo de caso serão distribuídas em três tópicos, precedidos da caracterização do ambiente onde se realizou a pesquisa. No primeiro tópico, se descreverá o modo como ocorreram as diferentes fases do ciclo de vida do Programa Mãe Curitibana, e em seguida se fará a caracterização dos processos de Gestão do Conhecimento nas referidas fases. Por fim, será apresentada a análise dos dados levantados acerca das contribuições dos processos de GC para a geração de benefícios, no âmbito do programa em estudo, em sua fase de operação.

\section{Caracterização do Ambiente da Pesquisa}

A Secretaria Municipal de Saúde (SMS) tem como missão "planejar e executar a política de saúde municipal, responsabilizando-se pela gestão e regulação dos serviços próprios e conveniados, monitorando doenças e agravos e realizando a vigilância sanitária sobre produtos e serviços de interesse da saúde, visando a uma população mais saudável" (CURITIBA, 2003, p. 225). Suas ações são desenvolvidas de maneira descentralizada, por intermédio de 08 (oito) Distritos Sanitários, compostos por Unidades de Saúde localizadas em sua área de abrangência geográfica. Em 1992, foram selecionadas e instauradas as Gerências Regionais de Saúde, bem como foram instituídas as Autoridades Sanitárias Locais, que, além de uma chefia única para as Unidades de Saúde, representam o poder público no campo da saúde, com responsabilidade sobre todo um território.

Dentro desse contexto, o Programa Mãe Curitibana, lançado oficialmente pela Prefeitura Municipal de Curitiba/Secretaria Municipal de Saúde (SMS), em março de 1999, é um programa de saúde materno-infantil por intermédio do qual se desenvolvem ações relacionadas a planejamento familiar, pré-natal, parto e puerpério, e saúde infantil, tendo como premissas básicas: maior segurança e qualidade no atendimento, vinculação das gestantes aos serviços de saúde e humanização do atendimento (CURITIBA, 1999a).

Os princípios norteadores do programa são a responsabilização da equipe pela saúde do binômio mãe-filho e a responsabilização de um Serviço Hospitalar de Referência pelo atendimento integral à gestante, destacando-se como suas principais metas: redução das mortes maternas e infantis; melhoria na atenção pré-natal; melhoria no acesso ao parto seguro no hospital e redução da transmissão vertical do HIV, toxoplasmose e sífilis $($ CURITIBA, 1999a).

\section{As Fases do Ciclo de Vida do Programa}

O ciclo de vida do Programa Mãe Curitibana iniciou-se em 1998, estendendo-se até o momento presente. A identificação das fases do ciclo de vida do Programa Mãe Curitibana, baseou-se na coleta de secundários, fundamentando-se nos conceitos explicitados no Quadro 1. 


\section{Quadro 1 - Fases e etapas/atividades do ciclo de vida de projetos}

\begin{tabular}{ll}
\hline Fases & Etapas/Atividades \\
\hline Formulação & surgimento da idéia do projeto (diagnóstico preliminar, demandas da população etc.); \\
& identificação do problema ou da necessidade que se pretendia resolver, do conjunto de \\
& possíveis beneficiários, da localização (abrangência) geográfica e dos objetivos a serem \\
& alcançados; \\
& formulação, preparação e escolha da alternativa de solução; \\
& avaliação ex-ante com vistas a identificar a conveniência da alternativa escolhida. \\
& planejamento e programação detalhada das atividades a serem executadas (desenho); \\
& implementação das atividades programadas (estruturação do programa); \\
& controle ou monitoramento das atividades de execução do projeto. \\
\hline Ostruturação & início do funcionamento; \\
& operação plena do projeto; \\
& acompanhamento da operação e avaliação ex-post do projeto. \\
\hline
\end{tabular}

Fonte: Elaborado com base em CEPAL/ILPES (2003).

A fase de formulação do Programa Mãe Curitibana aconteceu no período de setembro a dezembro de 1998. Forneceram subsídios, para a concepção do programa, estudos, pesquisas e experiência acumulada desde a década de 80 em programas de atenção integral à saúde da gestante (nos moldes do antigo Programa de Atenção Integral à Saúde da Mulher - PAISM) nas Unidades de Saúde da SMS, em parceria com as Sociedades Científicas, Universidades, Conselho de Municipal e Conselhos Locais de Saúde e Comitês de Mortalidade Materna.

Posteriormente à formulação do programa, no período de dezembro de 1998 a fevereiro de 1999, procedeu-se ao planejamento e à programação detalhada das atividades a serem executadas, bem como à implementação, ao controle e ao monitoramento destas atividades, com vistas a preparar a instituição para a implantação do programa.

O Programa Mãe Curitibana foi lançado, oficialmente, no dia 8 de março de 1999, num evento da SMS comemorativo ao Dia Internacional da Mulher. Seu funcionamento iniciou-se em maio de 1999, nas 92 (noventa e duas) Unidades de Saúde do Município que compõem a rede básica de saúde. As atividades realizadas na fase anterior, envolvendo os profissionais da SMS, Sociedades Científicas, Universidades, Maternidades e Conselho Municipal de Saúde, forneceram a sustentação para a implantação do programa.

Ao longo destas fases, foram identificadas diversas atividades intensivas em conhecimento, confirmando-se suas semelhanças com as práticas descritas pelos autores de Gestão do Conhecimento.

\section{Processos de Gestão do Conhecimento}

A caracterização dos processos de GC praticados no âmbito do Programa Mãe Curitibana, em suas diferentes fases, baseou-se na coleta de dados primários e secundários, fundamentando-se nos conceitos explicitados no Quadro 2. 


\section{Quadro 2 - Processos e práticas de gestão do conhecimento}

\begin{tabular}{ll}
\hline Processos & Práticas \\
\hline $\begin{array}{l}\text { Identificação do } \\
\text { conhecimento }\end{array}$ & $\begin{array}{l}\text { Identificação das competências críticas e das áreas de conhecimento relevantes } \\
\text { ao desenvolvimento do programa (de acordo com os objetivos estratégicos). } \\
\text { Identificação das lacunas entre as competências existentes e as necessárias. } \\
\text { Identificação das fontes internas e externas associadas às competências críticas } \\
\text { (áreas de conhecimento). }\end{array}$ \\
\hline Aquisição de conhecimento & $\begin{array}{l}\text { Aquisição de conhecimentos em fontes internas e externas, com foco no } \\
\text { desenvolvimento ou na manutenção das competências críticas para o } \\
\text { desenvolvimento do programa (lacunas de competências). }\end{array}$ \\
\hline Produção de conhecimento & $\begin{array}{l}\text { Criação, produção ou desenvolvimento de novos conhecimentos, no âmbito do } \\
\text { programa, por meio de estudos, análises e elaboração de propostas. }\end{array}$ \\
\hline $\begin{array}{l}\text { Sistematização de } \\
\text { conhecimento }\end{array}$ & $\begin{array}{l}\text { Registro de conhecimentos, habilidades e experiências relevantes para o } \\
\text { programa, em material impresso ou em meio eletrônico, com vistas a favorecer } \\
\text { sua disseminação entre os profissionais que atuam na sua operacionalização. }\end{array}$ \\
\hline $\begin{array}{l}\text { Compartilhamento de } \\
\text { conhecimento }\end{array}$ & $\begin{array}{l}\text { Acesso a conhecimentos, habilidades e experiências relevantes à } \\
\text { operacionalização do programa, por intermédio de material impresso e/ou } \\
\text { meio eletrônico; bem como, mediante troca direta entre profissionais que } \\
\text { atuam no programa, nos níveis central, distrital e local. }\end{array}$ \\
\hline Aplicação do conhecimento & $\begin{array}{l}\text { Aplicação dos conhecimentos disponíveis em situações práticas, com vistas a } \\
\text { gerar benefícios no âmbito do programa. }\end{array}$ \\
\hline
\end{tabular}

Fonte: Elaborado com base em Stollenwerk (2002), Probst, Raub, e Romhardt (2002), Davenport e Prusak (1998a, 1998b) e Peluffo A. e Catalan Contreras (2002).

Importante ressaltar que, dada a inexistência de iniciativas formalizadas de Gestão do Conhecimento na organização pesquisada, o mapeamento dos referidos processos/práticas no âmbito do Programa Mãe Curitibana focalizou-se sobre atividades semelhantes às práticas de GC utilizadas como referência para esta pesquisa, realizadas ao longo do ciclo de vida deste programa, aqui denominadas de práticas não formalizadas de Gestão do Conhecimento.

Por meio da pesquisa foi possível constatar um volume significativo de práticas não formalizadas de GC desenvolvidas ao longo das fases de formulação, estruturação e operação do Programa Mãe Curitibana, apresentadas, de maneira sucinta no Quadro 3.

Contudo, verificou-se que nem todas as práticas investigadas são realizadas no âmbito do programa; ou mesmo quando realizadas, nem sempre acontecem de acordo com o previsto. Além disso, constatou-se que os processos de aquisição, produção, sistematização, compartilhamento e aplicação do conhecimento nem sempre estão alinhados ao processo de identificação do conhecimento, o que resulta na fragmentação destas práticas.

Observou-se, ainda, que o modo e a freqüência com que essas práticas são realizadas refletem-se no processo de aplicação do conhecimento, que se baseia quase que exclusivamente em conhecimentos adquiridos por meio dos treinamentos sobre os protocolos (processo de aquisição de conhecimento). Isto demonstra o potencial ainda inexplorado das práticas de identificação, aquisição, produção, sistematização e compartilhamento do conhecimento, no sentido de favorecer o processo de aplicação do conhecimento e, conseqüentemente, a geração de benefícios, no âmbito do Programa Mãe Curitibana. 


\section{Quadro 3 - Processos/práticas de gc realizadas no programa mãe curitibana}

\begin{tabular}{|c|c|}
\hline $\begin{array}{l}\text { PROCESSOS } \\
\text { DE GC }\end{array}$ & PRÁTICAS REALIZADAS \\
\hline $\begin{array}{l}\text { Identificação do } \\
\text { conhecimento }\end{array}$ & $\begin{array}{l}\text { Definição e disseminação das atribuições dos profissionais que atuam no programa, por } \\
\text { meio de treinamentos e reuniões. } \\
\text { Delimitação das áreas de conhecimento do programa descrita em documentos } \\
\text { institucionais; } \\
\text { Identificação das necessidades de capacitação dos profissionais que atuam no programa } \\
\text { pela coordenação no nível central, em conjunto com as coordenações dos DS e autoridades } \\
\text { sanitárias locais e enfermeiras, ou por solicitação. } \\
\text { Identificação das fontes internas (profissionais do nível central, distrital e local) e externas } \\
\text { (sociedades científicas, universidades, entre outros) relacionadas às áreas de conhecimento } \\
\text { do programa, por parte do grupo de coordenação do programa. }\end{array}$ \\
\hline $\begin{array}{l}\text { Aquisição de } \\
\text { conhecimento }\end{array}$ & $\begin{array}{l}\text { Diversos treinamentos e cursos direcionados, de modo geral, a médicos e enfermeiros, } \\
\text { sobre os protocolos do programa, e demais temas relacionados à saúde materno-infantil. }\end{array}$ \\
\hline $\begin{array}{l}\text { Produção de } \\
\text { conhecimento }\end{array}$ & $\begin{array}{l}\text { Atividades voltadas à produção de estudos e análises sobre temas relacionados à saúde } \\
\text { materno-infantil, bem como elaboração de propostas relacionadas a fluxos e processo de } \\
\text { trabalho do Programa (atenção materno-infantil); realizadas, sobretudo, pelos profissionais } \\
\text { do nível central, em parceria com outros setores do mesmo nível, universidades e } \\
\text { sociedades científicas. }\end{array}$ \\
\hline $\begin{array}{l}\text { Sistematização de } \\
\text { conhecimento }\end{array}$ & $\begin{array}{l}\text { Iniciativas voltadas à sistematização de conhecimentos e experiências em material } \\
\text { impresso: formatação e reprodução de manuais, instruções normativas, protocolos, } \\
\text { sinopses de experiências vivenciadas nas US, boletins e revistas sobre temas relacionados } \\
\text { ao programa, realizados, sobretudo, pelos profissionais do nível central. }\end{array}$ \\
\hline $\begin{array}{l}\text { Compartilhamento } \\
\text { de conhecimento }\end{array}$ & $\begin{array}{l}\text { Acesso aos protocolos do programa e outros materiais encaminhados pela coordenação } \\
\text { (nível central) e participação em evento interno da SMS para troca de experiências; } \\
\text { participação de profissionais da coordenação (nível central) em diversos eventos nacionais } \\
\text { e internacionais para compartilhamento de conhecimentos e experiências relativos ao } \\
\text { programa. }\end{array}$ \\
\hline $\begin{array}{l}\text { Aplicação do } \\
\text { conhecimento }\end{array}$ & $\begin{array}{l}\text { Utilização de conhecimentos em situações práticas do programa, sobretudo os adquiridos } \\
\text { por meio da participação nos treinamentos e acesso aos próprios protocolos. }\end{array}$ \\
\hline
\end{tabular}

FONTE: elaborado com base na pesquisa de campo.

Especificamente no que se refere aos dados primários coletados por meio das entrevistas semi-estruturadas, merecem destaque as divergências de opiniões entre os profissionais que atuam no nível central/distrital (coordenações) e os que atuam no nível local (US), decorrentes, sobretudo, da freqüência e intensidade de seu envolvimento nas práticas apresentadas acima. Ao mesmo tempo identificou-se, por parte dos profissionais das US, o reconhecimento da relevância destas atividades, bem como de possíveis benefícios que poderiam ser desencadeados no programa, mediante sua ampliação.

Nesse sentido, merecem destaque as possibilidades de aperfeiçoamento dos processos/práticas de Gestão do Conhecimento, identificadas ao longo das entrevistas, sintetizadas no Quadro 4: 


\section{Quadro 4 - Ppossibilidades de aperfeiçoamento dos processos/práticas de gc no programa mãe curitibana,} identificadas ao longo das entrevistas

\begin{tabular}{|c|c|}
\hline PROCESSOS DE GC & POSSIBILIDADES DE APERFEIÇOAMENTO \\
\hline \multirow[t]{3}{*}{$\begin{array}{l}\text { Identificação do } \\
\text { conhecimento }\end{array}$} & $\begin{array}{l}\text { Aperfeiçoamento da forma como são definidas as atribuições e áreas de } \\
\text { conhecimento do programa, identificando-se as competências críticas e as áreas } \\
\text { de conhecimento que as sustentam (com base nos objetivos estratégicos do } \\
\text { programa, bastante conhecidos por todos). }\end{array}$ \\
\hline & $\begin{array}{l}\text { Ampliação da consulta aos profissionais das US, para identificação conjunta de } \\
\text { suas demandas de capacitação ou lacunas de competências, mediante } \\
\text { identificação prévia das competências críticas/áreas de conhecimento. }\end{array}$ \\
\hline & $\begin{array}{l}\text { Identificação e divulgação sistemática das fontes internas e externas, associadas } \\
\text { às competências críticas/áreas de conhecimento, com vistas a facilitar o acesso a } \\
\text { elas. }\end{array}$ \\
\hline $\begin{array}{l}\text { Aquisição de } \\
\text { conhecimento }\end{array}$ & $\begin{array}{l}\text { Expansão da quantidade e da cobertura dos cursos e treinamentos já realizados, } \\
\text { para outras categorias; em especial, para auxiliares de enfermagem. }\end{array}$ \\
\hline $\begin{array}{l}\text { Produção de } \\
\text { conhecimento }\end{array}$ & $\begin{array}{l}\text { Expansão da produção de estudos e análises já realizados no âmbito do } \\
\text { programa, sobretudo no nível local, mediante maior envolvimento dos } \\
\text { profissionais que atuam nas US. }\end{array}$ \\
\hline $\begin{array}{l}\text { Sistematização de } \\
\text { conhecimento }\end{array}$ & $\begin{array}{l}\text { Ampliação das práticas voltadas ao registro de conhecimentos e experiências, } \\
\text { sobretudo no nível local, mediante maior envolvimento dos profissionais das US. }\end{array}$ \\
\hline $\begin{array}{l}\text { Compartilhamento de } \\
\text { conhecimento }\end{array}$ & $\begin{array}{l}\text { Ampliação do acesso de profissionais das US a material impresso e/ou em meio } \\
\text { eletrônico; bem como maior envolvimento em atividades para troca direta de } \\
\text { conhecimentos entre profissionais que atuam no programa nos nível central, } \\
\text { distrital e local. }\end{array}$ \\
\hline $\begin{array}{l}\text { Aplicação do } \\
\text { conhecimento }\end{array}$ & $\begin{array}{l}\text { Expansão das práticas de aplicação, mediante ampliação e diversificação das } \\
\text { práticas de identificação, aquisição, produção, sistematização e compartilhamento } \\
\text { de conhecimento, conforme possibilidades explicitadas anteriormente. }\end{array}$ \\
\hline
\end{tabular}

FONTE: elaborado com base na pesquisa de campo.

Com base nos dados secundários e, especialmente, nos dados primários coletados por meio das entrevistas semi-estruturadas sobre os processos de GC, procedeu-se ao levantamento de dados sobre contribuições destes processos/práticas para a geração de benefícios intermediários no âmbito do Programa Mãe Curitibana, conforme tópico que se segue.

\section{Benefícios Intermediários da Gestão do Conhecimento}

$\mathrm{Na}$ revisão de literatura foram abordados os diferentes tipos de benefícios que podem resultar de atividades de Gestão do Conhecimento: diretos, intermediários e finais (WIIG, 2004). Importante ressaltar que a investigação sobre contribuições dos processos de GC para a geração de benefícios no Programa Mãe Curitibana concentrou-se nos benefícios intermediários, fundamentando-se nos conceitos explicitados no Quadro 5. 
Quadro 5 - Benefícios intermediários dos processos de gestão do conhecimento

\begin{tabular}{|l|l|}
\hline \multicolumn{1}{|c|}{ BENEFÍCIOS } & \multicolumn{1}{|c|}{ ITENS DE ANÁLISE } \\
\hline $\begin{array}{l}\text { Benefícios e Efeitos Internos (Foco nas } \\
\text { operações) }\end{array}$ & $\begin{array}{l}\text { Melhoria no desempenho dos profissionais que atuam na } \\
\text { operacionalização do Programa. } \\
\text { Melhoria nos fluxos e processos de trabalho do Programa. } \\
\text { Melhoria no processo de tomada de decisão e de } \\
\text { implementação de ações. }\end{array}$ \\
\hline $\begin{array}{l}\text { Benefícios no atendimento (Foco na } \\
\text { prestação dos serviços) }\end{array}$ & $\begin{array}{l}\text { Melhoria na adequação dos serviços às necessidades do } \\
\text { público-alvo. } \\
\text { Aumento da agilidade na prestação dos serviços. } \\
\text { Melhoria da qualidade na prestação dos serviços. }\end{array}$ \\
\hline $\begin{array}{l}\text { Benefícios e Reações Externos (Foco no } \\
\text { eúblico-alvo, organizações comunitárias }\end{array}$ & $\begin{array}{l}\text { Ampliação na adesão do público-alvo ao programa (acesso e } \\
\text { permanência). } \\
\text { Aumento da satisfação do público-alvo com os serviços } \\
\text { prestados. } \\
\text { Reconhecimento do programa pelas instituições parceiras e } \\
\text { organizações comunitárias. }\end{array}$ \\
\hline
\end{tabular}

FONTE: elaborado com base em Wiig (2004).

Conforme explicitado na metodologia, esse tópico da pesquisa concentrou-se exclusivamente na coleta de dados primários, levantados por meio de entrevistas semi-estruturadas com os profissionais das US e Coordenações.

No tocante às respostas em escala Likert, relativas às contribuições das práticas de GC para a geração de benefícios intermediários no âmbito do Programa Mãe Curitibana, observou-se um predomínio do percentual de concordância parcial, tanto por parte dos profissionais de coordenação, quanto dos profissionais de US, verificando-se uma tendência à valorização das atividades de GC já praticadas. Por outro lado, por meio do cálculo da média e do desvio padrão das respostas, observa-se que, enquanto no grupo de coordenadores ocorre certa concentração nas respostas, há maior variabilidade nas opiniões dos profissionais das US, entre as opções na escala, refletindo a diversidade de opiniões dentro do grupo quanto às contribuições dos processos não formalizados de GC, da forma como estes vêm ocorrendo atualmente. Também no grupo de profissionais das US, verifica-se maior frequiência de respostas discordantes, praticamente inexistentes no grupo de coordenadores.

De acordo com os dados levantados, os processos de Gestão do Conhecimento investigados, ainda que praticados de maneira não formalizada, vêm contribuindo de maneira significativa para a geração de benefícios intermediários no âmbito do Programa Mãe Curitibana, ou seja, para melhorias no funcionamento do programa, no atendimento ao público-alvo e no ambiente externo. Segundo os depoimentos dos entrevistados, tais contribuições ocorrem mediante aplicação de conhecimentos adquiridos por meio dos processos de GC investigados, sobretudo, por meio dos treinamentos sobre os protocolos (processo de aquisição).

Colheram-se alguns depoimentos dos entrevistados, por tipo de benefício intermediário investigado, que ilustram a forma como ocorrem estas contribuições.

Benefícios Internos (foco nas operações):

Pela padronização de fluxos, até pelo curso que está tendo... quando as pessoas começam a repensar os procedimentos, maior comprometimento... instiga questionamentos... pessoas saem do comodismo... (Entr. 10, US). 
Você trabalha melhor se tem maiores informações, se está mais atualizado... (Entr. 31, US).

[...] a capacitação do protocolo ajuda bastante a como você aplicar na US (Entr. 06, US).

[...] melhora o conhecimento, melhora o processo de trabalho (Entr. 19, US).

Benefícios no Atendimento (foco na prestação dos serviços):

[...] você conhecendo a área, a tua população, as dificuldades, até de entendimento da tua clientela, você conhecendo o nível social, tudo mais, você vai estar de repente conseguindo chegar mais próximo a tua informação a este usuário, vai estar facilitando o programa, de acordo com a clientela... então, você tem que realmente saber com que tipo de comunidade você está trabalhando... (Entr._16, US).

[...] com certeza, porque à medida que ele está sendo bem treinado, que ele tem mais informação, e os fluxos estão bem claros, está tudo organizado de uma forma bem... é claro que fica mais ágil... (Entr. 20, US).

[...] quando você busca o conhecimento, por exemplo, o protocolo já tem uma história, por exemplo, a toxoplasmose, o RH, o HIV, tudo em cima de casos, embasamento, dados científicos comprovados (atual e comprovado)... porque quando você estuda mais... você está buscando qualidade no atendimento... (Entr._20).

Benefícios Externos (foco no público-alvo, organizações comunitárias e instituições parceiras):

Se você tiver um atendimento que a tua paciente acha adequado, a paciente permanece no programa [...] ...existem algumas pacientes que procuram trocar de médico na US ...às vezes, tentar fazer o prénatal em outra US por causa do atendimento médico... (Entr. 11, US).

[...] porque se eu (gestante) tenho um serviço na minha área e o serviço é prestado com qualidade estou bem assistida... se o profissional conhece a área, sabe da tua realidade, você percebe que ele não é uma pessoa isolada, no consultório... quanto mais conhecimento, repercute na satisfação... (Entr. 33, Coord.).

[...] na maternidade (instituição parceira) tudo bate na questão da qualidade... ele (o médico) sabe se você mandar qualquer questão básica, porque o profissional não deu conta... a comunidade percebe a qualidade pela resolutividade, acompanham as taxas, número de reclamações... (Entr._35, Coord.).

Por outro lado, cabe ressaltar que, apesar dos altos níveis de concordância (parcial) em seus depoimentos, tanto os profissionais de Unidades de Saúde quanto os de Coordenações voltam a enfatizar as possibilidades de aperfeiçoamento das atividades não formalizadas de GC, apresentadas no Quadro 4, como condição para que haja uma concordância total em relação às contribuições destas práticas na geração de benefícios intermediários, no âmbito do Programa Mãe Curitibana.

Nesse sentido, nos comentários acerca das afirmativas relacionadas às contribuições das práticas de GC para a geração de benefícios intermediários, no âmbito do Programa Mãe Curitibana, foram destacadas as possibilidades de aperfeiçoamento das práticas relativas aos processos de aquisição, produção e compartilhamento de conhecimentos.

No tocante ao processo de aquisição de conhecimentos, voltam a enfatizar a necessidade de expansão dos treinamentos e dos momentos de repasse de conhecimentos para as demais categorias. Quanto ao processo de produção de conhecimentos, ressaltam as possibilidades de ampliação dos estudos relativos à saúde maternoinfantil, por suas possíveis repercussões no desempenho dos profissionais no processo de tomada de decisão e na adequação dos serviços às demandas do público-alvo. E, em relação ao processo de compartilhamento de conhecimentos, observam a possibilidade de expansão dos espaços para troca de conhecimentos e experiências entre os profissionais que atuam no programa, em especial quando se referem a melhorias na agilidade, no processo de tomada de decisão e na adequação dos serviços às demandas do público-alvo. 


\section{Conclusões}

Os resultados da pesquisa demonstram que as atividades de GC praticadas nas diferentes fases do ciclo de vida do Programa Mãe Curitibana vêm contribuindo significativamente para a geração, em seu âmbito, de benefícios intermediários, ou seja, para melhorias no seu funcionamento, no atendimento ao público-alvo e no ambiente externo, que ocorrem mediante aplicação de conhecimentos decorrentes dos processos/práticas de GC investigados, sobretudo daqueles adquiridos por meio dos treinamentos.

Nesse sentido, os resultados possibilitam constatar que estes benefícios intermediários são gerados, exclusivamente, pelo uso de conhecimentos em situações práticas do Programa Mãe Curitibana, ainda que adquiridos por meio dos demais processos. Tal situação confere especial destaque ao processo de aplicação do conhecimento, conforme representado na Figura 3.

\section{Figura 3 - Benefícios intermediários dos processos/práticas de gestão do conhecimento no programa mãe curitibana}

PROCESSOS DE GC

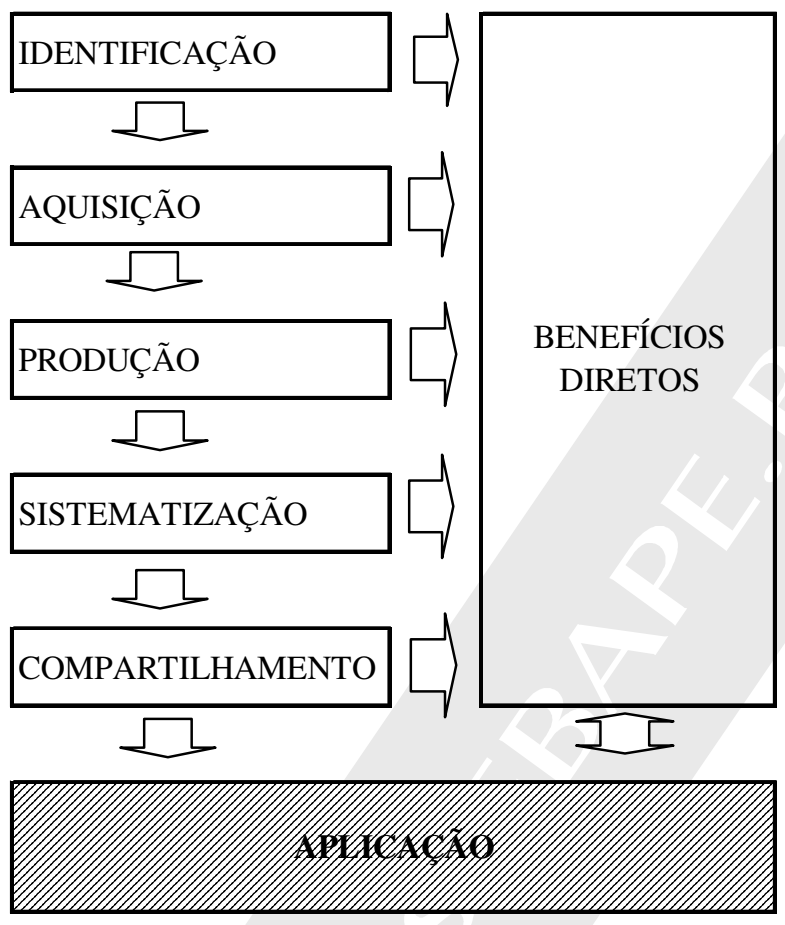

BENEFÍCIOS DA GC

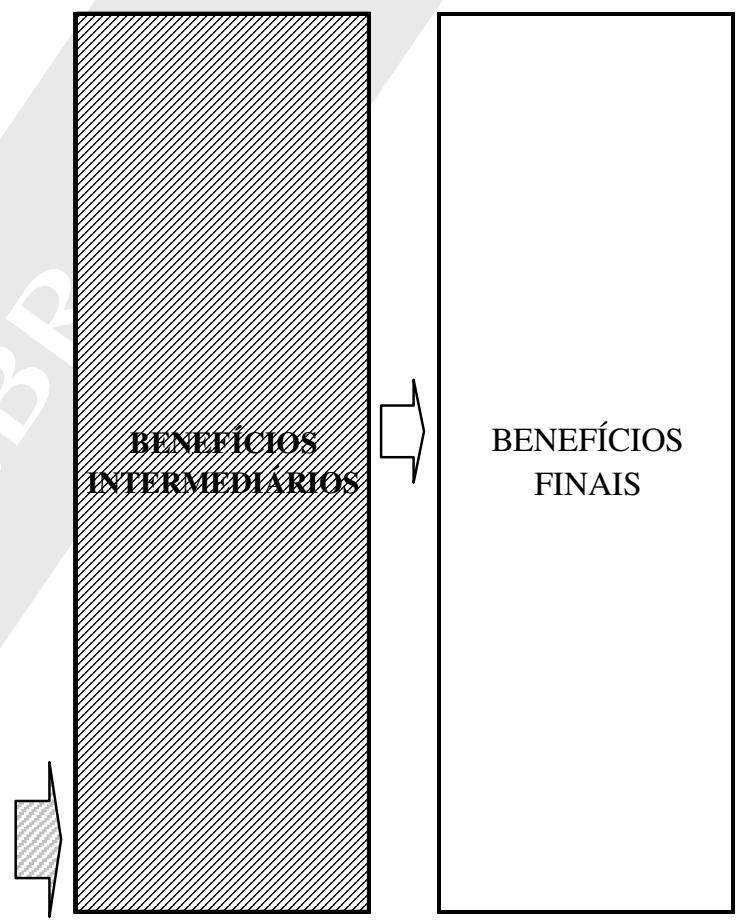

FONTE: elaborado com base em Stollenwerk (2002), Wiig $(1999,2004)$ e pesquisa de campo.

Por outro lado, ainda que o foco da pesquisa tenha se concentrado na identificação de benefícios intermediários, ao sugerir que tais atividades poderiam contribuir de maneira mais efetiva para a geração dos referidos benefícios no Programa Mãe Curitibana, os resultados possibilitam visualizar, também, os efeitos em cadeia das atividades de Gestão do Conhecimento, ou seja, possíveis desdobramentos das práticas de GC investigadas em benefícios diretos, intermediários e finais.

Dentro dessa lógica de pensamento, se consideradas as possibilidades de aperfeiçoamento apresentadas no Quadro 4, as práticas de identificação, aquisição, produção, sistematização e compartilhamento poderiam contribuir, como explicitado a seguir, de maneira mais intensiva para a geração de benefícios diretos: 
- identificação: maior clareza quanto a competências críticas, lacunas de competências e fontes de conhecimento a serem utilizadas como referência para as práticas de captura, criação, organização/armazenagem, compartilhamento do conhecimento e aplicação do conhecimento;

- aquisição e produção de conhecimentos: agregação de novos conhecimentos ao Programa, com foco nas competências críticas;

- sistematização: ampliação da base de conhecimentos explícitos no Programa, com foco nas competências críticas;

- compartilhamento: ampliação do acesso e distribuição de conhecimentos no Programa, com foco nas competências críticas.

Tais benefícios diretos poderiam, por sua vez, exercer maiores impactos sobre o processo de aplicação do conhecimento, favorecendo, conseqüentemente, a geração de benefícios intermediários (melhorias nos processos de trabalho, na prestação dos serviços e nas reações do cliente e do mercado) e benefícios finais (efeitos sobre as metas estratégicas do programa, tais como lucratividade e imagem de mercado, dentre outros).

De modo geral, os resultados da pesquisa demonstram a importância indiscutível do conhecimento no âmbito do Programa Mãe Curitibana. Contudo, informações relativas ao modo e à frequiência com que as práticas não formalizadas de GC vêm se realizando, assim como a ênfase conferida às possibilidades de aperfeiçoamento dessas atividades, apontam para a necessidade de reflexão acerca do conhecimento como um recurso estratégico, que necessita ser administrado com vistas a contribuir de maneira mais efetiva para a geração de benefícios em programas públicos. 


\section{Referências}

BARDIN, L. Análise de conteúdo. Lisboa: Edições 70, 1977.

BATISTA, F. F. 0 governo que aprende: gestão do conhecimento em organizações do executivo federal. Brasília: Ipea (Texto para Discussão n. 1022), 2004.

BATISTA, F. F. et al. Gestão do conhecimento na administração pública. Brasília: Ipea (Texto para Discussão n. 1095$), 2005$.

BRASIL. Ministério da Saúde. Cem palavras para a Gestão do Conhecimento. Brasilia: Ministério da Saúde, 2003.

Mapeamento de Gestão do Conhecimento. Disponivel em:<:http://www.gc.datasus.gov.br>. Acesso em: 25 maio 2004.

CARVALHO, I. Escola de governo em saúde: construindo um novo modelo de formação para o SUS. 2003. Disponível em: $<$ http://www.ensp.fiocruz.br >. Acesso em: 20 maio 2004.

CURITIBA. (Prefeitura Municipal). Secretaria Municipal de Saúde. Boletim Epidemiológico de Curitiba - Edição Especial Programa Mãe Curitibana. Curitiba, PR, maio 1999a.

CURITIBA. (Prefeitura Municipal). Instituto Municipal de Administração Pública. Relatório Anual de Atividades da PMC. Curitiba: IMAP, 2003.

DAVENPORT, T.; PRUSACK, L. Conhecimento empresarial. Rio de Janeiro: Campus, 1998 .

Ecologia da informação. São Paulo: Futura, 1998b.

DINSMORE, Paul C. Transformando estratégias empresariais através da gerência por projetos. Rio de Janeiro: Qualitymark, 1999.

FREITAS, H. M. R. et al. Pesquisa interativa e novas tecnologias para coleta e análise de dados usando o Sphinx. Canoas: Sphinx, 2002.

PELUFFO A., M. B.; CATALAN CONTRERAS, E. Introdución a la gestion del conocimiento y su aplicación al sector publico. Santiago de Chile: CEPAL. ECLAC, 2002. (Serie Manuales).

PROBST, Gilbert; RAUB, S.; ROMHARDT, K. Gestão do conhecimento: os elementos construtivos do sucesso. Porto Alegre: Bookman, 2002.

ROS, J. Measuring the benefits of knowledge management at the financial services authoriy: a case study. Jornal of Information Science, v. 29, n. 6, p. $475,2003$.

RUDIO, F. V. Introdução ao projeto de pesquisa científica. 29. ed. Petrópolis: Vozes, 2002.

SANTOS, Samara Beatriz; BARROS, José Carlos. Pesquisa de Marketing: Conceitos e Metodologias. 3 ed. São Paulo: Prentice Hall, 2002.

SKYRME, David. Knowledge management: beneficits tree. Disponivel em: <http//www.skyrme.com/tools/bentree.htm>. Acesso em: 8 jun. 2004.

STEWART, Thomas A. Capital intelectual. Rio de Janeiro: Campus, 1998.

STOLLENWERK. J. Gestão do Conhecimento: conceitos e modelos. In: TARAPANOFF, K. Inteligência Organizacional e Competitiva. Brasilia: Universidade de Brasília, 2002, p. 143-163.

TEIXEIRA FILHO, J. Gerenciando conhecimento: como a empresa pode usar a memória organizacional e a inteligência competitiva no desenvolvimento de negócios. Rio de Janeiro: Ed. SENAC, 2000.

TRIVINOS, A. N. S. Introdução à pesquisa em ciências sociais: a pesquisa, qualitativa em educação. São Paulo: Atlas, 1987.

VALERIANO, Dalton L. Gerência em projetos: pesquisa, desenvolvimento e engenharia. São Paulo: Makron Books, 1998.

VERZUH, Eric. MBA Compacto: gestão de projetos. Rio de Janeiro: Campus, 2000.

WIIG, K. M. Knowledge management methods: practical approaches to managing knowledge. Arlington, Texas: Schema, 1999 , v. 3.

WIIG, K. M. Aplication of knowledge management in public administration. Taiwan: Public Administrators of the City Taipei, 2000.

WIIG, K. M. Examples of knowledge management effects and benefits. 2000. Disponivel em: <http://www.krii.com.br/karl_wiig_pubs $>$. Acesso em: 24 fev. 2004.

YIN, R. K. Estudo de caso: planejamento e métodos. 2. ed. Porto Alegre: Bookman, 2001. 